\title{
Monitoring training loads: from training to competition
}

\author{
Zeghari L. ${ }^{\mathrm{ABCD}}$, Moufti H. ${ }^{\mathrm{ABCD}}$, Arfaoui A. ${ }^{\mathrm{CD}}$, Bougrine N. ${ }^{\mathrm{BD}}$, Tanda N. ${ }^{\mathrm{BC}}$ \\ Royal Institute of Management training, National Center of Sports Moulay Rachid, Salé, Morocco
}

Authors' Contribution: A - Study design; B - Data collection; C - Statistical analysis; D - Manuscript Preparation; E - Funds Collection.

\begin{abstract}
Purpose:

Monitoring is a new method that allows coaches and physical trainers to manage training in order to meet the needs of athletes. This study aims to evaluate through a scientific approach the homogeneity between the training program established by the coach in the pre-competition period, and the characteristics of the competition.

Material: $\quad$ The study was conducted at the FAR (Royal Armed Forces) Sports Association in Sale from February 10, 2019 to March 16, 2019, on a sample of 12 taekwondo athletes ( 5 girls and 7 boys), category "senior" with a middle age of $26.28 \pm 1.97$ for boys and $24.4 \pm 3.32$ for girls. The data collection concerns two different periods, the training and the competition period, in order to make a comparison between the different phases of the combat situations (preparation phase, exchange phase and recovery phase) during these two periods.

Results: $\quad$ For the combat in the training period we saw that the percentage of the preparation phase was $80.11 \%$, the exchange phase was $19.69 \%$, and the recovery phase was $0.18 \%$, however, in the competition period, the percentage of the preparation phase is $21.60 \%$, the exchange phase is $39.84 \%$, and the recovery phase is $38.54 \%$. The study of the correlation between the three phases of combat in the training period and the competition shows that there is no link between the different phases except between the exchange phase and the recovery phase (sig $=0.021<0.05$ ).

Conclusions: $\quad$ Our study was able to reveal that the requirements of the competition were not taken into consideration by the coach, which influenced the performance of the athletes during the competition. Therefore, a monitoring program is necessary in order to better plan the training and even predict the results of the competition.

Keywords: $\quad$ monitoring, taekwondo, training load, performance, competition, combat, Morocco.
\end{abstract}

\section{Introduction}

In preparing an athlete for a competition, we must consider two important criteria: the training load and the fatigue. Generally, any coach seeks to push the fatigue limits without exceeding the threshold at which the athlete risks overtraining $[1,2]$. This strategy is complicated to apply since a taekwondo coach addresses his/her athletes as a group and not as individuals, thus a standard workout can suit some athletes, while causing others to either under or over train, eventually impacting their competitiveness $[3,4]$.

Observing, monitoring and verifying the progress and quality of training over a set period of time are very important steps in determining if the training program is well suited for an athlete, and can help prevent injuries. This is defined as Monitoring. A new method that allows coaches and physical trainers to manage training to meet the needs of athletes [5]. The monitoring of athletes is becoming a necessity, and this to better understand the athlete and to know if the training carried out is coherent or not with the competition [6,7]. Despite the lack of data on high level athlete's publications, athlete tracking can provide an explanation of performance changes. This can help reduce the degree of uncertainty related to the results during the competition. More importantly, load monitoring is also put in place to reduce the risk of injury, especially in combat sports as taekwondo [8].

Hypothesis: the surveillance of athletes training may help the coach to determine the problems related

\footnotetext{
(c) Zeghari L., Moufti H., Arfaoui A., Bougrine N., Tanda N., 2019 doi:10.15561/18189172.2019.0508
}

to the training program, in order to prevent any kind of overtraining or athletes exhaustion, and also for a better training planning which will be in correlation with the competition requirement.

Purpose: The objective of our study is to evaluate by a scientific approach the conformity between the training established by coaches in the phase of preparation, and the characteristics of the competition.

\section{Material and methods:}

\section{Participants:}

The studied population consisted of 12 "senior" taekwondo athletes ( 5 girls and 7 boys), with a mean age of $26.28 \pm 1.97$ for boys and $24.4 \pm 3.32$ years for girls. They practice at the Royal Armed Forces Sports Club of Salé "FAR" league center. These athletes were qualified for the finale of Morocco's championship.

Research design:

The study focuses on the collection of several variables described in Table 1 and 2, in two different periods, training and competition, in order to make a comparison between combat situations during training and competition, the number of athletes participating for the training phase was 12 , of which only four will be followed in the competition phase due to the lack of materials and human resources to carry out the follow-up for the whole sample (12 athletes).

\section{Statistical analysis}

For the analysis of the link between the two groups we chose the study of correlation between the different phases 
Table 1. The different variables studied in the training phase

\begin{tabular}{ll}
\hline $\begin{array}{l}\text { Training Phase: } \\
\text { Variables }\end{array}$ & Objective \\
\hline & $\begin{array}{l}\text {-time ; } \\
\text { Warm up }\end{array}$ \\
& -nature : \\
& - General warm up ; \\
& - Specific warm up ; \\
Recovery time & The time taken for recovery \\
Cognitive engagement & the application time of the exercises explained by the coach \\
Motor Engagement & - Number of fights; \\
& - The duration of each phase of the fight \\
Combat situation & - The techniques performed in each fight; \\
& Method with which the athletes return to the initial state (stretching ....) \\
\hline
\end{tabular}

Table 2. The different variables studied in the competition phase

\begin{tabular}{ll}
\hline $\begin{array}{l}\text { Competition Phase } \\
\text { Variables }\end{array}$ & Objective \\
\hline & $\begin{array}{l}\text { This is the exploration phase, looking for rifts in the opponent's game, feints, } \\
\text { false attacks, displacements, footwork. } \\
\text { Preparation Phase } \\
\text { As soon as one of the two fighters triggers an action, we enter a so-called } \\
\text { exchange phase that ends with the last action of one of the two protagonists. An } \\
\text { exchange is constituted at least by an action (kick or punch) or more. } \\
\text { - The techniques performed in each fight } \\
\text { Corresponds to the time of passivity where the referee stops the game to } \\
\text { intervene and where the fighters do nothing. } \\
\text {-Nature: } \\
\text { Referee phase } \\
\text { recovery). } \\
\text {-The duration of passive recovery. }\end{array}$ \\
\end{tabular}

Table 3. Table representing the analysis of the warm-up part

\begin{tabular}{ll}
\hline Times & Duration (\%) \\
\hline T.T & $26 \min (100 \%)$ \\
S.T & $3 \min 22 \mathrm{~s}(11.53 \%)$ \\
E.T = T.T-ST & $23 \min 22 \mathrm{~s}(88,47 \%)$ \\
\hline
\end{tabular}

\section{Warming up:}

This table presents the analysis of the warm-up part which lasts in total (TT) 26 minutes, the stopping time (ST) is $3 \mathrm{~m} 22 \mathrm{~s}$ and that of effort (ET) is $23 \min 22 \mathrm{~s}$ and represents a percentage of $88,47 \%$ of the total time.

Note: T.T: total time, S.T: stopping time, E.T: effort time, R: recovery.

Table 4. Table showing the analysis of the motor Engagement (effort time) part.

\begin{tabular}{ll}
\hline Times & Duration $(\%)$ \\
\hline E.T & $32,84 \min (80,87 \%)$ \\
S.T & $5 \min (9,85 \%)$ \\
R & $3,98 \mathrm{~ms}(9,80 \%)$ \\
\hline
\end{tabular}

\section{Motor Engagement:}

The table shows that the motor engagement time or the effort time represents $80.87 \%$ of the total time, the sopping time represents $9.85 \%$, and the recovery time represents $9.80 \%$.

Note: T.T: total time, S.T: stopping time, E.T: effort time, R: recovery. 
of the combat in the training and in the competition, with the software SPSS version 25.

And for the monitoring and data collection we used:

-An observation sheet;

-A stopwatch;

-A camera;

-Software SPSS;

-DARTFISH software.

\section{Results}

Training phase:

The average duration of sessions of the program 1h48min (tabl. 3, 4).

Recovery time analysis:

According to the analysis of this phase we note that the recovery was active with a percentage of $13.01 \%$ of the total time of the session which corresponds to $12 \mathrm{~min} 12 \mathrm{~s}$.

Analysis of combat situations:

According to the results obtained throughout the program, the time devoted to combat situations represents 8 minutes $(11.13 \%)$ of the total time.

Analysis of the combat phases in the training: From the table below, we note that the percentage of the preparation phase is $80.11 \%$, the exchange phase is $19.69 \%$, and finally the recovery phase with a percentage of $0.18 \%$.

Table 5. Evaluation of the combat phases in training

\begin{tabular}{lll} 
training & & \\
\hline Combat Phases & Duration & Percentage \\
\hline Preparation phase & $01 \mathrm{~min} 07 \mathrm{~s} 00 \mathrm{~ms}$ & $80,11 \%$ \\
exchange phase & Omin 31s 22ms & $19,69 \%$ \\
recovery phase & Omin00s30ms & $0,18 \%$ \\
\hline
\end{tabular}

Competition phase:

This table represents the characteristics of each subject, as well as the results of the competition.

Table 6. Characteristics of the subjects studied

\begin{tabular}{lllll}
\hline subjects & $\begin{array}{l}\text { height } \\
\text { (m) }\end{array}$ & $\begin{array}{l}\text { weight } \\
\mathbf{( k g )}\end{array}$ & gender & $\begin{array}{l}\text { competition } \\
\text { result }\end{array}$ \\
\hline $\mathbf{1}$ & 1,93 & 87 & male & wins \\
$\mathbf{2}$ & 1,71 & 58 & female & wins \\
$\mathbf{3}$ & 1,60 & 46 & male & lose \\
$\mathbf{4}$ & 1,90 & 68 & female & lose \\
\hline
\end{tabular}

Analysis of the combat phases for the 4 subjects From the table below, we note that the average percentage of the preparation phase is $21.60 \%$, the exchange phase is $39.84 \%$, and finally the recovery phase with a percentage of $38.54 \%$.

Table 7. Evaluation of the combat phases in the competition.

\begin{tabular}{lll}
\hline $\begin{array}{l}\text { Competition } \\
\text { combat phases }\end{array}$ & Durée & Percentage \\
\hline preparation phase & $01 \mathrm{~min} 22 \mathrm{~s} 00 \mathrm{~ms}$ & $21,60 \%$ \\
exchange phase & $2 \mathrm{~min} 31 \mathrm{~s} 22 \mathrm{~ms}$ & $39,84 \%$ \\
recovery phase & $2 \mathrm{~min} 26 \mathrm{~s} 30 \mathrm{~ms}$ & $38,54 \%$ \\
\hline
\end{tabular}

-The correlation between combat in training and competition:

According to the table below, there is a difference between the techniques used, the number of shots and the points scored by each technique between the fight in the training phase and the fight in the competition phase.

From Table 9 we find that there is a significant correlation between the exchange phase and the recovery phase $(\mathrm{sig}=0.021<0.05)$. While there is no correlation between the other phases of training and competition.

\section{Discussion}

At the international level, many coaches and physical trainers are taking an increasingly scientific approach to design and monitor their training programs, whereas in Morocco these approaches are rarely used. This demonstrate itself by the huge lack of bibliography in this sense, despite the fact that the training supervision allows to reach a sufficiently large load to improve the targeted qualities, with managing the magnitude of the fatigue that can lead to the fateful threshold leading to the injury $[9,10]$. With this in mind, we sought to identify the gaps that may exist between training and competition in the precompetitive period among qualified taekwondo athletes practicing within the FAR Sports Association in Salé, Morocco.

The descriptive analysis of the training phase allows us to see that the average duration of the sessions of the program that was $1 \mathrm{~h} 48 \mathrm{~min}$, the warm-up time lasts in total before each session 26 minutes which is a good result, due to the role warm-up in the prevention of injuries during intense training sessions [11].

The analysis of the training program allows us to say that the athletes work the same training program, which is explained by the fact that the coach does not follow the most important training principle, which is individualization. It is a fundamental factor for the progression of athletes, and allows to establish a training program according to the athlete's abilities, characteristics and needs [12-15].

Calculating the average part of the combat situation throughout the entire program, we found out its percentage to be around (11.13\%). It is a very small and negligible result given that the athletes were in a precompetition period. This negligible percentage does not benefit athletes since it doesn't give them the opportunity to experience combat situations as part of their training in order to ready themselves for real matches [12].

From these results, we found that there is no correlation between the different phases of the combat during training and during the competition, which proves that the training plan does not support the characteristics of the competition, except between exchange and recovery $(\operatorname{sig}=0.021<0.05)$, which can be explained by the fact that the more the exchange time (effort time) increases the more the athlete needs time to recover [16-19].

Several techniques used by the athletes in the competition have not been established in the training program namely; DWITT TCHAGUI for athlete number 2 and subject 4 on the table 8 , who used this technique in 
Table 8. Analysis of techniques used during training combat and those used in competitive combat:

\begin{tabular}{|c|c|c|c|c|c|}
\hline \multirow{2}{*}{ Subjects } & \multirow{2}{*}{ Techniques } & \multicolumn{2}{|l|}{ Training } & \multicolumn{2}{|l|}{ competition } \\
\hline & & Shots number & points scored & Shots number & Points scored \\
\hline \multirow{6}{*}{1} & YOP TCHAGUI & 10 & 4 & 3 & 0 \\
\hline & DOLYEU TCHAGUI & 18 & 9 & 39 & 7 \\
\hline & MON DOLYEU TCHAGUI & 0 & 0 & 0 & 0 \\
\hline & DWITT TCHAGUI & 9 & 2 & 4 & 1 \\
\hline & NELYEU TCHAGUI & 5 & 0 & 2 & 3 \\
\hline & PUNCHE & 12 & 8 & 8 & 3 \\
\hline \multirow{6}{*}{2} & YOP TCHAGUI & 12 & 3 & 1 & 1 \\
\hline & DOLYEU TCHAGUI & 24 & 8 & 20 & 1 \\
\hline & MON DOLYEU TCHAGUI & 0 & 0 & 0 & 0 \\
\hline & DWITT TCHAGUI & 0 & 0 & 13 & 2 \\
\hline & NELYEU TCHAGUI & 8 & 2 & 0 & 0 \\
\hline & PUNCHE & 12 & 4 & 17 & 3 \\
\hline \multirow{7}{*}{3} & YOP TCHAGUI & 12 & 6 & 10 & 0 \\
\hline & DOLYEU TCHAGUI & 21 & 3 & 76 & 4 \\
\hline & MON DOLYEU TCHAGUI & 0 & 0 & 0 & 0 \\
\hline & DWITT TCHAGUI & 5 & 0 & 1 & 0 \\
\hline & NELYEU TCHAGUI & 4 & 3 & 0 & 0 \\
\hline & PUNCHE & 6 & 4 & 10 & 5 \\
\hline & HITCHEU & 2 & 0 & 0 & 0 \\
\hline \multirow{6}{*}{4} & YOP TCHAGUI & 17 & 5 & 6 & 0 \\
\hline & DOLYEU TCHAGUI & 12 & 3 & 31 & 4 \\
\hline & MON DOLYEU TCHAGUI & 0 & 0 & 0 & 0 \\
\hline & DWITT TCHAGUI & 0 & 0 & 9 & 0 \\
\hline & NELYEU TCHAGUI & 2 & 0 & 2 & 0 \\
\hline & PUNCHE & 6 & 1 & 12 & 0 \\
\hline
\end{tabular}

Table 9. Correlation between the preparation phase, exchange and recovery in training and competition.

\begin{tabular}{|c|c|c|c|c|c|}
\hline \multirow{2}{*}{ Indicators } & & & \multicolumn{3}{|c|}{ Training phase } \\
\hline & & & Preparation & Exchange & Recovery \\
\hline & Preparation & - C. c-Sig.(bilateral) & 1,000 & 0,095 & 0,279 \\
\hline \multirow[t]{2}{*}{ Competition } & & & & 0,823 & 0,503 \\
\hline & Exchange & -C. c & 0,095 & 1,000 & 0,786 \\
\hline \multirow[t]{3}{*}{ Phase } & & -Sig.(bilateral) & 0,823 & & $0,021 *$ \\
\hline & Recovery & - C. C & 0,279 & 0,786 & 1,0000 \\
\hline & & -Sig.(bilateral) & 0,503 & $0,021 *$ & \\
\hline
\end{tabular}

\section{*. The correlation is significant at the $\mathbf{0 . 0 5}$ (bilateral). C.C: coefficient of correlation}

the competition without being able to try it in the training period.

\section{Conclusion}

The monitoring or the surveillance of athletes using technological tools, can help the coach to fairly judge their athletes, and to better program trainings that are based on tangible data. This study revealed that the requirements of the competition were not taken in consideration by the coach, which influenced the performance of the athletes during the competition. However, this method can also be used to analyze the game of potential opponents during the preparation stage of competitions.

\section{Acknowledgement}

To the entire staff of the Royal Armed Forces Sports Club of Salé, and especially to the coach Mr. Tanda Abdellah for his valuable contribution and advice throughout the realization of this work.

\section{Contributions of the authors}

All the authors contributed to the conduct of this work.

\section{Conflicts of interest}

There is no conflict of interest. 


\section{References}

1. Gabbett TJ, Hulin BT, Blanch P, Whiteley R. High training workloads alone do not cause sports injuries: how you get there is the real issue. British Journal of Sports Medicine 2016;50:444-5. https://doi.org/10.1136/bjsports-2015-095567

2. Jagiello W, Jagiello M, Kalina RM, Barczynski BJ, Litwiniuk A, Klimczak J. Properties of body composition of female representatives of the Polish national fencing team - the sabre event. Biology of Sport. 2017;34(4):401-406. https://doi.org/10.5114/biolsport.2017.70526

3. Maso F. Analyse et interprétation du questionnaire de la Société française de médecine du sport pour la détection de signes précoces de surentraînement : étude multicentrique. Science \& Sports. 2005; 20(12-20): 20. https://doi.org/10.1016/j.scispo.2004.05.013

4. Volodchenko OA, Podrigalo LV, Iermakov SS, Zychowska MT, Jagiello W. The Usefulness of Performing Biochemical Tests in the Saliva of Kickboxing Athletes in the Dynamic of Training. Biomed Research International, 2019:2014347. https://doi.org/10.1155/2019/2014347

5. Halson SL, Jeukendrup AE. Does overtraining exist?. Sports medicine. 2004;34(14): 967-981. https://doi.org/10.2165/00007256-200434140-00003

6. Halson S.L. Monitoring training load to understand fatigue in athletes. Sports medicine. 2014;44(2): 139-147. https://doi.org/10.1007/s40279-014-0253-z

7. Doroshenko EY, Svatyev AV, Iermakov SS, Jagiello W. The use of cardio training facilities in training 7-9-year-old judo athletes. Archives of Budo Science of Martial Arts and Extreme Sports. 2017;13:165-72.

8. Pieter W, Fife GP, O'sullivan DM. Competition injuries in taekwondo: A literature review and suggestions for prevention and surveillance. Br J Sports Med. 2012;46(0): 485-491. https://doi.org/10.1136/bjsports-2012-091011

9. Lystad R, Pollard H, Graham P. Epidemiology of injuries in competition taekwondo: A meta-analysis of observational studies. J Sci Med Sport. 2009;12(6):614-621. https://doi.org/10.1016/j.jsams.2008.09.013

10.Sedeaud $A$, sène $\mathrm{Jm}$, krantz $\mathrm{N}$, saulière $\mathrm{G}$. The importance of quantifying training loads: A model example. Sci Sports. 2017;0(0):11. https://doi.org/10.1016/j.scispo.2017.06.011

11.BishopD,PotentialMechanisms and theEffects ofPassiveWarm UponExercisePerformance.Sports Med.2003;33(6):439-454. https://doi.org/10.2165/00007256-200333060-00005

12.Kazemi M, Shearer H, Su Choung Y. Precompetition habits and injuries in Taekwondo athletes. BMC Musculoskeletal Disorders, 2005;6:26. https://doi.org/10.1186/1471-2474-6-26

13.Oleksy M, Kalina RM, Mosler D, Jagiello W. Quasiapparatus shime waza test (QASWT) - validation procedure. Archives of Budo, 2018;14:133-47.

14.Viru A. The mechanism of training effects: a hypothesis. Int $J$ Sports Med. 1984;0(5): 219-227. https://doi.org/10.1055/s-2008-1025909

15.Bompa T. Theory and methodology of training: the key to athletic performance. Kendall hunt publishing company; 1983.

16.Kenttä G, Hassmén P. Overtraining and recovery. Sports medicine. 1998;26(1): 1-16. https://doi.org/10.2165/00007256-199826010-00001

17.Jagiello W. Differentiation of the body composition in taekwondo-ITF competitors of the men's Polish national team and direct based athletes. Archives of Budo. 2015;11:329-38.

18.Kuipers H. How much is too much? Performance aspects of overtraining. Res $Q$ Exerc Sport. 1996;67(3): 65-69. https://doi.org/10.1080/02701367.1996.10608855

19.O'Connor, PJ. Overtraining and staleness. In: Morgan WP (Ed.), Series in health psychology and behavioral medicine. Physical activity and mental health, Philadelphia, PA, US: Taylor \& Francis; 1997. P. 145-160.

\section{Information about the authors:}

Zeghari L.; (Corresponding author); https://orcid.org/0000-0001-6769-6864; zegharilotfi@gmail.com; Royal Institute of Management training, National Center of Sports Moulay Rachid, Salé; National Center of Sports Moulay Rachid, Road of Meknes Km 12, Salé, Morocco.

Moufti H.; http://orcid.org/0000-0001-6421-1454; h_moufti@yahoo.fr; Royal Institute of Management training, National Center of Sports Moulay Rachid, Salé; National Center of Sports Moulay Rachid, Road of Meknes Km 12, Salé, Morocco.

Arfaoui A.; http://orcid.org/0000-0002-5705-2536; amine_arfaoui@yahoo.fr; Royal Institute of Management training, National Center of Sports Moulay Rachid, Salé; National Center of Sports Moulay Rachid, Road of Meknes Km 12, Salé, Morocco.

Bougrine N.; https://orcid.org/0000-0002-6735-2823 ; Nadiabougrine68@gmail.com; Royal Institute of Management training, National Center of Sports Moulay Rachid, Salé; National Center of Sports Moulay Rachid, Road of Meknes Km 12, Salé, Morocco.

Tanda N.; https://orcid.org/0000-0002-6022-5055; tkd99naoual@gmail.com; Royal Institute of Management training, National Center of Sports Moulay Rachid, Salé; National Center of Sports Moulay Rachid, Road of Meknes Km 12, Salé, Morocco..

Cite this article as:

Zeghari L, Moufti H, Arfaoui A, Bougrine N, Tanda N. Monitoring training loads: from training to competition. Pedagogics, psychology, medical-biological problems of physical training and sports, 2019;23(5):262-266. https://doi.org/10.15561/18189172.2019.0508

This is an Open Access article distributed under the terms of the Creative Commons Attribution License, which permits unrestricted use, distribution, and reproduction in any medium, provided the original work is properly cited (http://creativecommons.org/licenses/by/4.0/deed.en). 